\title{
Los hechos pueden marcar un antes y un después
}

\author{
Facts can mark a before and an after \\ Juan Ramón Cisneros Ochoa* \\ * Expresidente de la FEMECOT
}

Se sabe que la escritura surgió como una necesidad de registrar datos administrativos en las civilizaciones de la Mesopotamia al final del IV milenio a.C. Fue un hecho tan relevante que divide las dos etapas de la humanidad, «la Historia y la Prehistoria». A través de los siglos de historia se pudo con ella documentar el pasado, establecer y consultar normas y leyes que hacen la vida más justa, transmitir los sentimientos, heredar la cultura, ejercer el arte con la novela o la poesía, fue el principal medio de comunicación del conocimiento y la ciencia hasta el siglo XIX, con la invención del telégrafo en 1836. A partir de esta fecha, surgen nuevos medios de comunicación como la radio, el teléfono, el teletipo y la televisión electrónica con las primeras transmisiones comerciales en 1927. Fue hasta finales de los sesenta, en 1969, durante la Guerra Fría, que se creó la Internet con fines militares, medio que crece y evoluciona hasta 1991 que se establece como se le conoce actualmente, «World Wide Web» (WWW). Se vuelve tan importante como medio de comunicación que es posible establecer dos nuevas etapas: «antes y después de Internet».
Mi generación como residente de Ortopedia fue de 1979 a 1983, pertenecemos a la etapa de antes de Internet, para nosotros cualquier trabajo de investigación requería consultar sólo medios escritos, era lento, a veces difícil y caro, la suscripción a revistas era poco accesible para un médico en formación, por lo que se recurría a la hemeroteca para leer y obtener copias. En la actualidad es tan fácil obtener información, que sólo se requiere un poco de voluntad para actualizarnos, investigar y documentar científicamente nuestro trabajo.

Invito, sobre todo a los jóvenes, a que aprovechen esta oportunidad para que, a través de la revista Orthotips que está renovándose con una total apertura, compartan sus experiencias, seguro todos hemos implementado o mejorado una técnica, tuvimos un caso inédito o tenemos una idea para mejorar un implante o hacer más amigable el instrumental.

Investigar y publicar es tan importante que nos libera de la dependencia de tecnologías importadas, enaltece nuestra profesión y sobre todo beneficia a nuestros pacientes. 